\title{
The role of lymphadenectomy at the time of radical nephroureterectomy for upper tract urothelial carcinoma
}

\author{
Michael E. Goltzman, Augustyna Gogoj, Benjamin T. Ristau \\ Division of Urology, UConn Health, Farmington, CT, USA \\ Contributions: (I) Conception and design: BT Ristau; (II) Administrative support: BT Ristau; (III) Provision of study material or patients: BT Ristau; \\ (IV) Collection and assembly of data: None; (V) Data analysis and interpretation: None; (VI) Manuscript writing: All authors; (VII) Final approval of \\ manuscript: All authors. \\ Correspondence to: Benjamin T. Ristau, MD, MHA. Assistant Professor of Surgery, Surgical Director of Urologic Oncology, Division of Urology \\ I UConn Health, 263 Farmington Avenue, Farmington, CT 06030, USA. Email: benristaumd@gmail.com.
}

\begin{abstract}
The role of lymphadenectomy (LND) at the time of radical nephroureterectomy (RNU) for upper tract urothelial carcinoma (UTUC) is controversial. The National Comprehensive Cancer Network guidelines recommend performing a template-based LND for high-risk primary tumors while the European guidelines state that it is not feasible to determine indication or extent of LND at the time of surgery for UTUC. Herein, we review the anatomic rationale for template-based LND, examine when a LND should be considered, and discuss the impact of LND on staging and survival outcomes.
\end{abstract}

Keywords: Upper tract urothelial carcinoma (UTUC); lymphadenectomy; nephroureterectomy; metastasis; treatment outcome

Submitted Oct 23, 2019. Accepted for publication Nov 18, 2019.

doi: $10.21037 /$ tau.2019.11.29

View this article at: http://dx.doi.org/10.21037/tau.2019.11.29

\section{Introduction}

Upper tract urothelial carcinoma (UTUC) is an uncommon malignancy. Since incidence estimates are often lumped together with renal parenchymal tumors, the true contemporary epidemiology is somewhat difficult to obtain (1). The annual incidence of renal pelvic and ureteral tumors was 1 and 0.73 per 100,000 person-years based on Surveillance Epidemiology and End Results (SEER) data from 1985 to 1994 (2). As such, UTUC accounts for $5 \%$ of all urothelial malignancies and $10 \%$ of all renal tumors with an estimated 3,500 cases in the United States each year.

Lymphatic involvement occurs in approximately 20-30\% of patients who undergo radical nephroureterectomy (RNU) (3-5). Sites of lymph node invasion are dependent on the location of the primary tumor with paracaval, interaortocaval, and para-aortic involvement for renal pelvic and proximal to mid ureteral tumors and pelvic lymph node involvement with more distal ureteral tumors $(3,6)$.

Pelvic lymphadenectomy is a standard part of the surgical approach for bladder urothelial carcinoma, serving primarily as a staging procedure since up to $25 \%$ of patients with bladder urothelial carcinoma harbor pelvic lymph node metastases at the time of surgery (7). The role of lymph node dissection (LND) for patients with UTUC is less clear. Current guidelines recommendations are controversial with NCCN Guidelines recommending LND in patients with high-grade tumors and European Guidelines stating that it is not feasible to determine indication or extent of LND in UTUC $(8,9)$. Herein, we review the evidence base to determine when LND may be appropriate in UTUC and what dissection templates should be considered when LND is performed.

\section{Lymphatics of the upper urinary tract and patterns of lymphatic metastasis}

Anatomically, the renal lymphatics drain from the kidney towards the renal hilum. From here, the lymphatic drainage is similar between the kidney and proximal ureter, but 


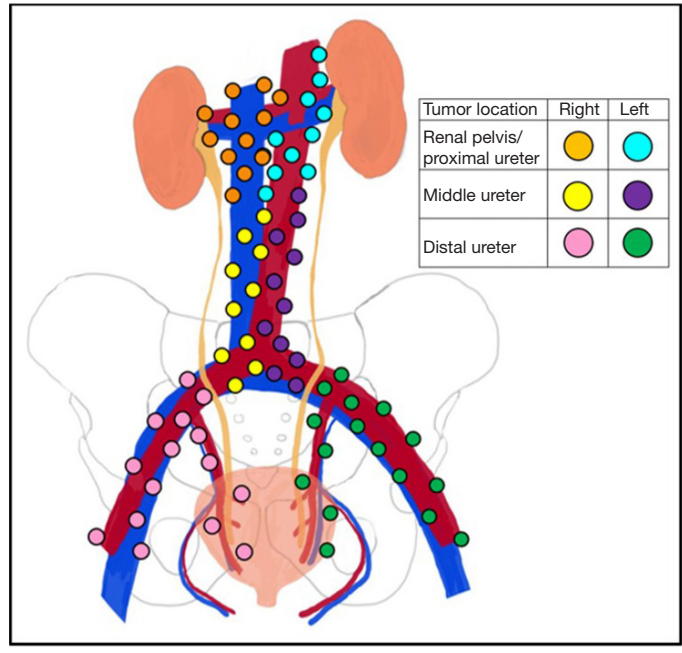

Figure 1 Lymphatic drainage for upper tract urothelial cancers by location.

differs from side to side. On the right, lymphatic channels feed into paracaval, pre- and retrocaval, and interaortocaval lymph node basins. On the left, the drainage runs to paraaortic, pre- and retro-aortic, and interaortocaval lymph nodes. In the right mid-ureter, lymphatic fluid runs towards the paracaval and interaortocaval lymph nodes while the left drainage is mostly to the para-aortic lymph nodes. The distal ureter is drained by common, external, and internal iliac lymph nodes for each respective side (Figure 1) (10).

The region of lymphatic metastases in UTUC is dependent on the location of the primary tumor. Kondo and colleagues were the first to examine the pattern of lymph node metastasis for UTUC in 42 patients with documented lymph node metastasis (3). Tumors from the renal pelvic and upper ureter metastasized in $20-30 \%$ of cases while patients with distal ureteral tumors were noted to have metastasis in $10 \%$. Primary tumors in the right renal pelvis metastasized to the renal hilar, paracaval, and retrocaval lymph nodes while those on the left demonstrated lymph node involvement in the renal hilar and para-aortic chains. Involvement of the retrocaval and interaortocaval lymph nodes were noted for primary tumors in the right mid ureter while left mid ureteral cancers spread primarily to para-aortic lymph nodes. For distal ureteral masses, lymph node invasion was observed in the common iliac chain.

Matin and colleagues pooled data from multiple institutions to examine patterns of lymphatic metastasis in 73 patients with lymph node positive UTUC (6). For the renal pelvis and proximal ureter on the right, lymph node metastases were detected in hilar, paracaval, retrocaval, and interaortocaval regions. On the left, positive lymph nodes were found in hilar, para-aortic, interaortocaval, suprahilar $(\mathrm{n}=1)$, common iliac $(\mathrm{n}=1)$, aortic bifurcation, and retrocrural $(n=1)$ locations. Notably, the few patients with left-sided renal pelvic or proximal ureteral primary tumors who had lymph node metastases outside the traditionally expected drainage basins also had positive lymph nodes in the hilar and paracaval area. Moreover, interaortocaval lymph nodes were noted along with more common areas of metastatic spread (i.e., hilar and paracaval on the right AND hilar and para-aortic on the left) in all but one case suggested secondary involvement of interaortocaval lymph nodes in most cases.

Lymph node metastases were noted in para-aortic, hilar, and internal iliac lymph nodes in patients with left mid ureteral primary cancers. Patients with distal ureteral masses had positive lymph nodes detected primarily in the common, internal, and external iliac lymph node chains. However, on both sides cephalad drainage to paracaval (right) and para-aortic (left) was observed.

\section{Template for lymphadenectomy in patients with UTUC}

The manuscripts from Kondo and Matin form the basis of our current understanding about what lymph nodes to remove during RNU for UTUC $(3,6)$. The basic template is largely guided by primary tumor location. For the purposes of this review and proposal of a data-driven LND template (Figure 2), data from both studies were combined. For primary tumors of the renal pelvis and proximal ureter on the right side, a hilar, paracaval, and retrocaval LND would identify $83.1 \%$ of all patients with metastases. Including the interaortocaval lymph nodes would bring this total to $100 \%$. Of note, approximately half of patients with positive interaortocaval lymph nodes had synchronous metastases in the hilar or paracaval lymph nodes. For primary tumors of the right mid ureter, interaortocaval LND identified $66.7 \%$ of patients with metastases and inclusion of paracaval lymph nodes brought this to $100 \%$. Of note, this included only 3 patients; more data are needed to define the template. For tumors of the distal right ureter, a pelvic dissection (obturator and common, external, and internal iliac) would capture $75 \%$ of all patients with metastases and extension to paracaval lymph nodes would identify all patients.

On the left, hilar and para-aortic LND captured 93.4\% of all patients with metastases for primary tumors of the 


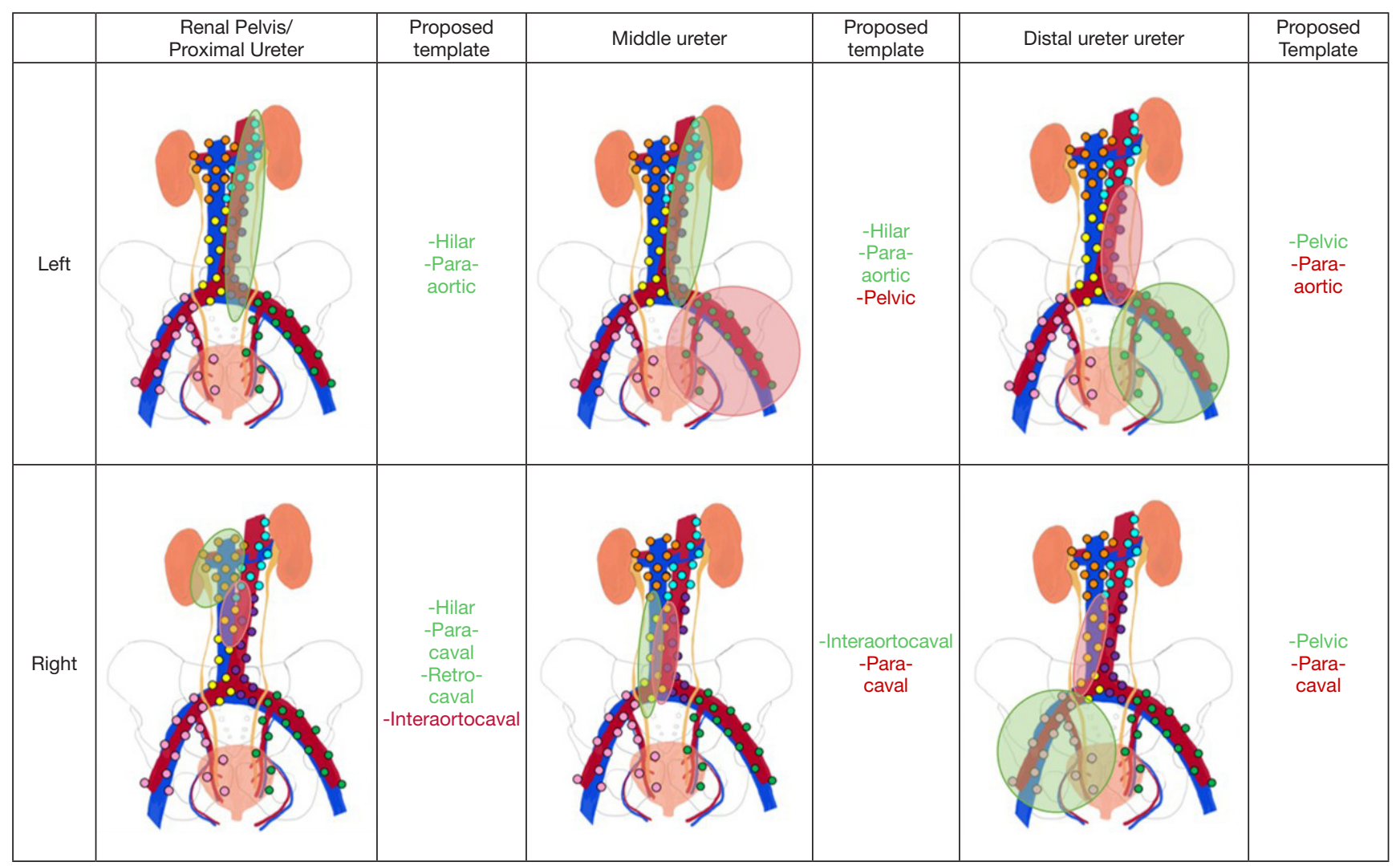

Figure 2 Proposed templates for upper tract urothelial carcinoma. Standard (green) and extended (red) as described by Kondo et al. (3) and Matin et al. (6).

renal pelvis and proximal ureter. For left mid ureteral tumors, para-aotic and hilar lymph nodes harbored $87.5 \%$ of all lymph node metastases. Inclusion of pelvic lymph nodes would bring this total to $100 \%$. For tumors of the distal right ureter, pelvic LND would capture $75 \%$ of all patients with lymph node metastases and inclusion of the para-aotic lymph nodes would bring this total to $100 \%$. Since overall numbers are low, more data are needed to definitively determine optimal LND templates in UTUC.

\section{When to consider including LND at the time of RNU for UTUC}

The decision to perform any surgical procedure should be based on an assessment of risk and after shared decisionmaking with the patient. There are two primary proposed risk factors for the presence of lymph node metastasis in UTUC: tumor grade and stage.

Miyake et al. showed an increasing risk of lymph node involvement with high grade tumors $(70 \%)$ relative to intermediate (24\%) and low-grade tumors (8\%) (11). Similarly, Kondo and colleagues demonstrated a higher risk of positive lymph nodes in patients with high-grade disease $(35 \%)$ compared to intermediate $(11 \%)$ and lowgrade disease $(0 \%)$. Finally, Roscigno et al. demonstrated lymph node involvement in $28.9 \%$ of patients with highgrade disease compared to $9 \%$ of patients with low-grade disease (12). Importantly, many of these low-grade patients were selected to undergo LND compared to omitting LND, which leads to overestimation of the true incidence of metastasis for patients with low-grade UTUC.

Tumor stage is another factor associated with the presence of lymph node metastasis in UTUC. Miyake and colleagues demonstrated lymph node invasion in $9 \%$ pTa, 20\% pT1, 44\% pT2, 71\% pT3, and 100\% pT4.11 Kondo et al showed $0 \%$ for $\mathrm{pTis} / \mathrm{pTa} / \mathrm{pT} 1,5 \%$ for $\mathrm{pT} 2$, $24 \%$ for $\mathrm{pT} 3$, and $85 \%$ for pT4 tumors. 3 Roscigno and colleagues demonstrated lymph node involvement in $6.3 \%$ of pT $1,16.8 \%$ of pT2, and $35 \%$ of patients with pT3-4 tumors. Tumor stage can be challenging to determine pre- 
Table 1 Cancer-specific survival of patients undergoing lymphadenectomy in patients undergoing radical nephroureterectomy for the management of upper tract urothelial carcinoma

\begin{tabular}{|c|c|c|c|c|c|c|c|}
\hline Study & Year & $\begin{array}{l}\text { Study } \\
\text { design }\end{array}$ & \multicolumn{2}{|c|}{ Number of patients, n (\%) } & \multicolumn{2}{|r|}{ css } & $\begin{array}{l}\text { Follow-up, } \\
\text { mos (range) }\end{array}$ \\
\hline $\begin{array}{l}\text { Lughezanni } \\
\text { et al. (15) }\end{array}$ & 2010 & Retrospective & NoLND 747 (26.5) & LND 2077 (73.5) & $5-\mathrm{yr}$ CSS $=77.8 \%$ & $5-y r$ CSS $=81.2 \%$ & $\begin{array}{c}\text { Mean/median } \\
59.7 / 43.0(0,1-203)\end{array}$ \\
\hline $\begin{array}{l}\text { Cho } \\
\text { et al. (16) }\end{array}$ & 2009 & Retrospective & NoLND 89 (58.6) & LND 63 (41.4) & $5-\mathrm{yr}$ CSS $=62.7 \%$ & $5-y r$ CSS $=71 \%$ & Median 53 (6-214) \\
\hline $\begin{array}{l}\text { Abe } \\
\text { et al. (17) }\end{array}$ & 2008 & Retrospective & NoLND 146 (46.8) & LND 166 (53.2) & $5-\mathrm{yr}$ CSS $=64.7 \%$ & $\begin{array}{l}\text { pN0 5-yr CSS }=88.4 \% \\
\text { pNy 5-yr CSS }=22.3 \%\end{array}$ & Median 47 (1-194) \\
\hline $\begin{array}{l}\text { Secin } \\
\text { et al. (4) }\end{array}$ & 2007 & Retrospective & NoLND 119 (47.2) & LND 133 (52.8) & $5-\mathrm{yr}$ CSS $=56 \%$ & $\begin{array}{l}\text { pN0 5-yr CSS }=73 \% \\
\text { pNy } 5-y r \text { CSS }=0 \%\end{array}$ & Median 37.2 (NR) \\
\hline $\begin{array}{l}\text { Kondo } \\
\text { et al. (19) }\end{array}$ & 2007 & Retrospective & NoLND 88 (52.1) & $\begin{array}{l}\text { ILND } 36 \text { (21.3) } \\
\text { CLND } 45 \text { (26.6) }\end{array}$ & NR & NR & $\begin{array}{c}\text { Mean/median } \\
49.0 / 37.3(1-209)\end{array}$ \\
\hline $\begin{array}{l}\text { Miyake } \\
\text { et al. (11) }\end{array}$ & 1998 & Retrospective & NoLND 37 (51.4) & LND 35 (48.6) & $\begin{array}{l}3-y r \text { CSS }=65 \% \\
5-y r \text { CSS }=50 \%\end{array}$ & $\begin{array}{l}3-\mathrm{yr} \text { CSS }=73 \% \\
5-\mathrm{yr} \text { CSS }=50 \%\end{array}$ & Mean 49 (7-116) \\
\hline
\end{tabular}

CSS, Cancer-specific survival; NoLND, no lymphadenectomy; CLND, complete lymphadenectomy; ILND, incomplete lymphadenectomy; T-BLND, template-based lymphadenectomy; NR, not reported; RP, renal pelvis; U, ureter.

operatively due to difficulties obtaining adequate tissue at biopsy to determine depth of invasion.

These risk factors align with current NCCN recommendations stating that template-based LND should be performed in patients with high-grade histology, large $(>3-4 \mathrm{~cm})$ primaries, or tumors with parenchymal invasion.

An important component of shared-decision making involves a discussion of potential complications for a given procedure. A prospective analysis of 19 patients undergoing RNU with LND reported 9 complications (13). Of these 8 were Clavien I-II (ileus, lymphatic leak, blood transfusions) and 1 was Clavien IIIB (chylous leak requiring return to OR). Abe and colleagues examined complications associated with RNU and LND in 45 consecutive patients (14). Six patients had Clavien I-II complications and 1 patient a Clavien 5 complication following GI bleed and aspiration pneumonia. Thus, based on prospective studies, only one major complication (chylous leak requiring return to $\mathrm{OR}$ ) occurred that was attributable to LND.

Offering LND to patients at high risk of metastasis (high-grade, large, and/or invasive tumors) is reasonable and confers an acceptably low risk of complication over RNU.

\section{Impact of LND on survival in patients with UTUC}

The overall impact of LND on survival outcomes in UTUC is controversial with some studies demonstrating benefit while others show no difference (Table 1). Miyake and colleagues examined outcomes of 72 patients who underwent RNU for UTUC (11). Of these, 35 patients underwent concomitant LND. There were no significant differences between groups in age, tumor location, grade, or stage. The authors found no difference in overall survival (OS) between patients who underwent LND $(58 \%)$ and those who did not $(50 \%)$. In a subset without lymphovascular invasion (LVI), there was a significant difference in 5 -year OS favoring LND ( $86 \%$ vs. $50 \%$ ). The authors concluded that patients with LVI likely have systemic disease and therefore are more likely to benefit from systemic therapy rather than LND.

Brausi et al. performed a retrospective review of 82 
patients who underwent RNU for UTUC, 40 of whom had a LND performed (18). Patients who underwent LND tended to have higher grade and higher stage tumors compared to the no LND group. The median time to recurrence was 51.2 months in the LND group relative to 18.5 months in the no LND group $(\mathrm{P}=0.01)$. Similarly median OS was better for patients in the LND group (52.5 months) compared to the no LND group (21.2 months, $\mathrm{P}<0.01)$. Notably, there was no mention of receipt of adjuvant therapy between the two groups, which may partially explain these differences. Nonetheless, these authors report improved OS in patients who underwent LND.

Secin and colleagues examined 133 patients who underwent LND at the time of RNU compared to 119 who had RNU alone (4). Positive urine cytology was associated with increased likelihood of LND being performed (OR 2.53, 95\% CI: 1.21-5.28). Three-year cancer-specific survival (CSS) was $79 \%$ for N0, $80 \%$ for $\mathrm{Nx}$, and $41 \%$ for $\mathrm{N}+$ patients. There was no significant survival difference between $\mathrm{N} 0$ and $\mathrm{Nx}$ patients $(\mathrm{P}=0.4)$. The authors concluded that LND improves staging and may help select patients for adjuvant systemic therapy.

Kondo et al. looked at the impact of extent of LND at the time of RNU in 45 patients who underwent complete LND, 36 patients who underwent incomplete LND, and 88 patients in whom LND was not performed (19). Taken together, there was no significant difference in CSS among the three groups. However, in patients with pT3-4 primary tumors ( $\mathrm{n}=88$ ), performance of LND was associated with improved cancer specific survival $(\mathrm{P}=0.01$, effect size not written).

Abe and colleagues performed a multi-institutional, retrospective review on 312 patients who had RNU (17). Of these, 166 had LND performed. Five-year CSS was $88.4 \%$ for $\mathrm{pN} 0,64.7 \%$ for $\mathrm{pNx}$, and $22.3 \%$ for $\mathrm{pN}+$ patients. There was a significant difference in survival between the $\mathrm{pN} 0$ and $\mathrm{pNx}$ groups $(\mathrm{P}<0.001)$. Interestingly, there was no survival differences noted based on the number of lymph nodes removed $(\mathrm{P}=0.465$ for comparison of $1-5,6-10$, or $>11$ LNs removed). The authors summarized these findings by suggesting that LND is an important part of adequate staging during RNU for UTUC and may provide a therapeutic benefit.

Cho et al. retrospectively reviewed 62 patients who underwent LND at the time of RNU and compared the data to 90 patients who had RNU alone (16) There were no differences in 5 -year recurrence-free survival $(55.0 \%$ vs.
$58.2 \%, \mathrm{P}=0.67)$ or CSS (71\% vs. $62.7 \%, \mathrm{P}=0.95)$ between LND and no LND groups. The authors concluded that LND may improve staging, but does not influence survival.

Roscigno and colleagues evaluated data on 1,132 patients undergoing RNU including 552 who had LND (12). Five-year CSS was similar between patients who underwent LND (66\%) and did not undergo (69\%) LND ( $\mathrm{P}=0.23)$. However, patients with $\mathrm{pNx}$ demonstrated worse CSS compared to $\mathrm{pN} 0$ patients $(69 \%$ vs. $77 \%, \mathrm{P}<0.01)$. There was no difference in CSS between $\mathrm{pNx}$ and $\mathrm{pN} 0$ groups in patients with pT1 primary tumors $(86 \%$ vs. $90 \%, \mathrm{P}=0.16)$, which likely reflects the low incidence of metastasis in this population. For patients with pT2-T4 disease, CSS was $58 \%$ for $\mathrm{pNx}$ compared to $70 \%$ for $\mathrm{pN} 0$. Moreover, patients who did not undergo LND (i.e., $\mathrm{pNx}$ ) in the pT2T4 cohort had lower probability of CSS compared to $\mathrm{pN} 0$ patients (HR 1.42, $\mathrm{P}=0.016)$. The authors concluded that LND improves staging and identifies patients who may benefit from adjuvant systemic therapy.

Lughezzani et al. examined the SEER database in an effort to help determine the impact of LND on survival in UTUC (15). A total of 1,835 patients were confirmed pN0 while 242 patients were $\mathrm{pN}+$ and 747 patients did not have LND performed ( $\mathrm{pNx})$. $\mathrm{pNx}$ patients had larger, higher grade tumors and were operated on in more historic years. There was no significant difference in 5 -year CSS between $\mathrm{pNx}(77.8 \%)$ and $\mathrm{pN} 0(81.2 \%, \mathrm{P}=0.09)$. This lack of difference was confirmed in the population with pT2-4 primary tumors $(71.3 \%$ vs. $73.9 \%, \mathrm{P}=0.4)$. Therefore, the authors propose that LND in all patients undergoing LND may not be justified.

A major limitation of the aforementioned studies is their retrospective nature. As such, there are no standardized indications or template for LND. Furthermore, neoadjuvant or adjuvant systemic therapies were not applied based on specific criteria. Even still, the bulk of these data suggest that LND may not itself provide a therapeutic benefit. Instead, the rationale for LND in high-risk patients may be to better identify and select patients for adjuvant systemic therapies since many of these patients ultimately succumb to metastatic disease.

\section{The impact of the number of lymph nodes removed}

Critics of the observed lack of therapeutic benefit for LND in UTUC may point to the adequacy of the extent of LND performed. To that end, some have looked at the impact of 
lymph node yield on survival outcomes in UTUC.

Roscigno et al. evaluated 552 patients who underwent RNU and LND from 13 different centers (20). Removal of 13 lymph nodes resulted in a $90 \%$ chance of detecting a positive lymph node while removing 8 lymph nodes identified $75 \%$ of pN+ patients. Removing more than 15 lymph nodes did not result in a significant incremental benefit for the detection of positive lymph nodes. The authors suggest that patients with fewer than 8 lymph nodes removed may require closer follow-up since they may have been understaged.

Winer and colleagues identified 442 patients who underwent RNU with LND for UTUC (21). The median number of lymph nodes removed was 9 (IQR 4-16). No difference in RFS or CSS was observed based on extent of LND performed for the whole cohort. However, RFS was better in patients with positive lymph nodes if more lymph nodes were removed (HR per 5 lymph nodes $0.84,95 \% \mathrm{CI}$ : $0.71-0.99, \mathrm{P}=0.04)$.

In the previously mentioned study by Abe et al. (14), a subanalysis of outcome based on extent of LND was performed. First, patients were stratified into zero, 1-5, or greater than 5 lymph nodes removed. No difference in CSS was observed. Next, patients were regrouped into $1-5,5-10$, or greater than 10 lymph nodes removed. Even still, the authors were unable to demonstrate a survival benefit based on the number of lymph nodes removed. Similarly, Cho and colleagues stratified patients into $0,1-6$, and greater than 6 lymph nodes removed (16). No differences in RFS or CSS were noted.

There are problems with using number of lymph nodes removed as a surrogate for the adequacy of LND. First, there is significant variability in number of lymph nodes within a given template from patient to patient. For example, in the recently reported German randomized trial of LND extent in bladder cancer (LEA), lymph node counts ranged from 12-26 in the limited arm and 22-47 in the extended arm (7). Second, thoroughness of pathologic review may vary from institution to institution or even within the same institution based on whether specimens are submitted en bloc or in separate packets (22). Therefore, we prefer a thorough template-based dissection rather than reliance on the number of lymph nodes removed to determine the adequacy of LND.

\section{Lymphadenectomy in UTUC: survival benefit or valuable staging procedure?}

It is unlikely that LND itself contributes substantially to improved survival in most patients with UTUC. Despite retrospective data hinting at a potential survival benefit, randomized trials in bladder, prostate, breast, and pancreatic cancer have failed to demonstrate improvement in recurrence or survival with performance or extension of LND (7,23-25).

Retrospective studies that attribute improved oncologic outcomes to performance or extension of template LND may suffer from a bias known as the Will-Rogers effect. Will Rogers was an Oklahoman comedian who quipped that when the Okies left Oklahoma and moved to California, the average intelligence of both states increased. The implication was that the folks leaving Oklahoma were not as intelligent as those who stayed (why would one ever leave Oklahoma?), but were more intelligent than Californians.

The Will-Rogers phenomenon has been applied to describe stage migration in cancer and apparent changes in survival outcomes $(26,27)$. For example, if one does not perform a $\mathrm{LND}(\mathrm{pNx})$, there are a subset of patients who will harbor lymph node metastatic disease. However, if the perfect LND is performed, patients are stratified into those without metastasis $(\mathrm{pN} 0)$ and those with metastasis $(\mathrm{pN}+)$. Therefore, pN0 patients appear to have better outcomes than $\mathrm{pNx}$ patients since all patients with lymph node positive disease have been removed in the $\mathrm{pN} 0$ group (under perfect circumstances).

A similar phenomenon is observed if standard versus extended LND templates or few versus greater number of lymph nodes removed are examined under the same lens (Figure 3). This occurs because patients with low volume metastatic disease not identified in standard LND are removed from the pN0 group and appropriately re-staged to the $\mathrm{pN}+$ group. This has the effect of more accurately identifying true pN0 patients and adding lower volume lymph node positive patients to the $\mathrm{pN}+$ group. In effect, both groups apparently do better because of the LND.

This is not to say that the performance of LND is futile, particularly in UTUC. It is critical to appropriately stage patients with UTUC in order to identify those suitable for adjuvant therapy. Randomized trial evidence has demonstrated a progression-free survival advantage for adjuvant chemotherapy in high-risk patients (28). Therefore, LND plays an important staging role in selecting patients for adjuvant therapies following nephroureterectomy for UTUC.

\section{Summary and conclusions}

The role of LND at the time of RNU in UTUC remains 


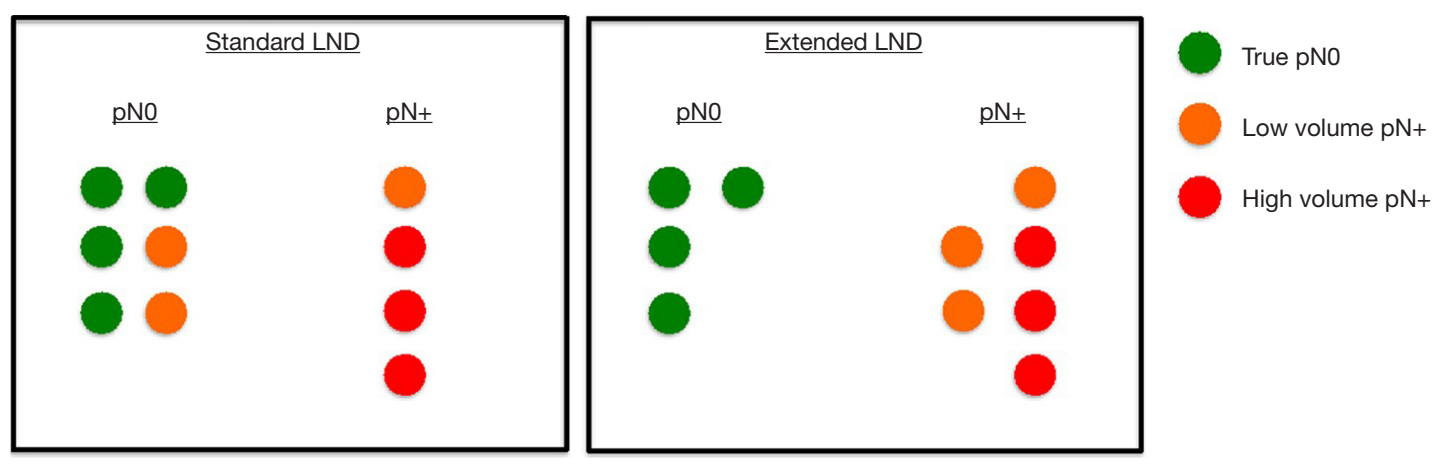

Figure 3 Standard versus extended lymphadenectomy and the Will Rogers phenomenon.

controversial given the uncertain impact of LND on survival outcomes. Current NCCN guidelines support LND for high-risk tumors: specifically, for high-grade histology, large $(>3-4 \mathrm{~cm})$ primaries, and for tumors with apparent parenchymal invasion. While LND may not confer a direct survival benefit, there is no question that it provides more accurate staging. Since there is randomized trial evidence that adjuvant chemotherapy may benefit patients at high risk, proper staging is critically important. Therefore, templatebased LND at the time of RNU for these high-risk patients is recommended.

\section{Acknowledgments}

Funding: None.

\section{Footnote}

Provenance and Peer Review: This article was commissioned by the Guest Editors (John J. Knoedler and Jay D. Raman) for the series "Upper-Tract Urothelial Carcinoma: Current State and Future Directions" published in Translational Andrology and Urology. The article was sent for external peer review organized by the Guest Editors and the editorial office.

Conflicts of Interest: All authors have completed the ICMJE uniform disclosure form (available at http://dx.doi. org/10.21037/tau.2019.11.29). The series "Upper-Tract Urothelial Carcinoma: Current State and Future Directions" was commissioned by the editorial office without any funding or sponsorship. The authors have no other conflicts of interest to declare.

Etbical Statement: The authors are accountable for all aspects of the work in ensuring that questions related to the accuracy or integrity of any part of the work are appropriately investigated and resolved.

Open Access Statement: This is an Open Access article distributed in accordance with the Creative Commons Attribution-NonCommercial-NoDerivs 4.0 International License (CC BY-NC-ND 4.0), which permits the noncommercial replication and distribution of the article with the strict proviso that no changes or edits are made and the original work is properly cited (including links to both the formal publication through the relevant DOI and the license). See: https://creativecommons.org/licenses/by-nc-nd/4.0/.

\section{References}

1. Siegel RL, Miller KD, Jemal A. Cancer statistics, 2019 (US statistics). CA Cancer J Clin 2019; 69:7-34.

2. Munoz JJ, Ellison LM. Upper tract urothelial neoplasms: Incidence and survival during the last 2 decades. J Urol 2000;164:1523-5.

3. Kondo T, Nakazawa H, Ito F, et al. Primary Site and Incidence of Lymph Node Metastases in Urothelial Carcinoma of Upper Urinary Tract. Urology 2007;69:265-9.

4. Secin FP, Koppie TM, Salamanca JIM, et al. Evaluation of regional lymph node dissection in patients with upper urinary tract urothelial cancer. Int J Urol 2007;14:26-32.

5. Ozsahin $M$, Zouhair A, Villà $S$, et al. Prognostic factors in urothelial renal pelvis and ureter tumours: A multicentre rare cancer network study. Eur J Cancer 1999;35:738-43.

6. Matin SF, Sfakianos JP, Espiritu PN, et al. Patterns of lymphatic metastases in upper tract urothelial carcinoma and proposed dissection templates. J Urol 2015;194:1567-74.

7. Gschwend JE, Heck MM, Lehmann J, et al. Extended Versus Limited Lymph Node Dissection in Bladder Cancer 
Patients Undergoing Radical Cystectomy: Survival Results from a Prospective, Randomized Trial. Eur Urol 2019;75:604-11.

8. National Comprehensive Cancer Network: Bladder Cancer (Version 4.2019).

9. Rouprêt M, Babjuk M, Compérat E, et al. European Association of Urology Guidelines on Upper Urinary Tract Urothelial Carcinoma: 2017 Update. Eur Urol 2018;73:111-22.

10. Anderson JK, Caddedu JA. Surgical Anatomy of the Retroperitoneum. In: Campbell-Walsh Urology. Philadelphia, PA: Elsevier; 2012.

11. Miyake H, Kara I, Gohji K, et al. The significance of lymphadenectomy in transitional cell carcinoma of the upper urinary tract. Br J Urol 1998; 82:494-8.

12. Roscigno M, Shariat SF, Margulis V, et al. Impact of Lymph Node Dissection on Cancer Specific Survival in Patients With Upper Tract Urothelial Carcinoma Treated With Radical Nephroureterectomy. J Urol 2009;181:2482-9.

13. Rao SR, Correa JJ, Sexton WJ, et al. Prospective clinical trial of the feasibility and safety of modified retroperitoneal lymph node dissection at time of nephroureterectomy for upper tract urothelial carcinoma. BJU Int 2012;110:E475-80.

14. Abe T, Takada N, Matsumoto R, et al. Outcome of regional lymphadenectomy in accordance with primary tumor location on laparoscopic nephroureterectomy for urothelial carcinoma of the upper urinary tract: A prospective study. J Endourol 2015;29:304-9.

15. Lughezzani G, Jeldres C, Isbarn H, et al. A Critical Appraisal of the Value of Lymph Node Dissection at Nephroureterectomy for Upper Tract Urothelial Carcinoma. Urology 2010;75:118-24.

16. Cho KS, Choi HM, Koo K, et al. Clinical significance of lymph node dissection in patients with muscle-invasive upper urinary tract transitional cell carcinoma treated with nephroureterectomy. J Korean Med Sci 2009;24:674-8.

17. Abe T, Shinohara N, Harabayashi T, et al. The role of lymph-node dissection in the treatment of upper urinary tract cancer: a multi-institutional study. BJU Int 2008;102:576-80.

18. Brausi MA, Gavioli M, De Luca G, et al. Retroperitoneal lymph node dissection (RPLD) in conjunction with nephroureterectomy in the treatment of infiltrative transitional cell carcinoma (TCC) of the upper urinary tract: impact on survival. Eur Urol 2007;52:1414-8.

19. Kondo T, Nakazawa H, Ito F, et al. Impact of the extent of regional lymphadenectomy on the survival of patients with urothelial carcinoma of the upper urinary tract. J Urol 2007;178:1212-7.

20. Roscigno M, Shariat SF, Freschi M, et al. Assessment of the Minimum Number of Lymph Nodes Needed to Detect Lymph Node Invasion at Radical Nephroureterectomy in Patients With Upper Tract Urothelial Cancer. Urology 2009;74:1070-4.

21. Winer AG, Vertosick EA, Ghanaat M, et al. Prognostic value of lymph node yield during nephroureterectomy for upper tract urothelial carcinoma. Urol Oncol 2017;35:151. e9-151.e15.

22. Bochner BH, Herr HW, Reuter VE. Impact of separate versus en bloc pelvic lymph node dissection on the number of lymph nodes retrieved in cystectomy specimens. J Urol 2001;166:2295-6.

23. Touijer K, Sjoberg D, Benfante N, et al. MP54-10 Comparison Between Limited and Extended Lymph Node Dissection For Prostate Cancer: Results from a Large, Clinically-Indicated, Randomized Trial. J Urol 2019;201:e788.

24. Giuliano AE, Ballman K V., McCall L, et al. Effect of axillary dissection vs no axillary dissection on 10 -year overall survival among women with invasive breast cancer and sentinel node metastasis: The ACOSOG Z0011 (Alliance) randomized clinical trial. JAMA 2017;318:918-26.

25. Sasako M, Sano T, Yamamoto S, et al. D2 lymphadenectomy alone or with para-aortic nodal dissection for gastric cancer. N Engl J Med 2008;359:453-62.

26. Feinstein AR, Sosin DM, Wells CK. The Will Rogers Phenomenon: Stage Migration and New Diagnostic Techniques as a Source of Misleading Statistics for Survival in Cancer. N Engl J Med 1985;312:1604-8.

27. Albertsen PC, Hanley JAH, Barrows GH, et al. Prostate cancer and the Will Rogers phenomenon. J Natl Cancer Inst 2005;97:1248-53.

28. Birtle AJ, Chester JD, Jones RJ, et al. Results of POUT: A phase III randomised trial of perioperative chemotherapy versus surveillance in upper tract urothelial cancer (UTUC). J Clin Oncol 2018;36:abstr 407.

Cite this article as: Goltzman ME, Gogoj A, Ristau BT. The role of lymphadenectomy at the time of radical nephroureterectomy for upper tract urothelial carcinoma. Transl Androl Urol 2020;9(4):1860-1867. doi: 10.21037/ tau.2019.11.29 